\title{
Study on the Ecological Evolution and Growth Mechanism of the Brand
}

\author{
Huabin Wang \\ School of Design \\ South China University of Technology \\ Guangzhou, China 510640
}

\author{
Yu Chen* \\ School of Design \\ South China University of Technology \\ Guangzhou, China 510640 \\ *Corresponding author
}

\begin{abstract}
The theory of the brand rose to the idea of life body, and then proposed the ecological brand system research which gradually appears, while the relevant research is limited. On the basis of predecessors' research, this paper summarizes the ecological evolution and systematic characteristics of the brand, extending to summarize the several class characteristics of the brand, and discussing the principle mechanism of the ecology evolution of brand and its growth momentum based on these characteristics. It helps to respect the ecological and systematic rules in the process of brand construction and provide useful reference for brand operation and management.
\end{abstract}

Keywords-Brand; Ecology; Bionic characteristics; Growth mechanism

\section{INTRODUCTION}

In 1859, Darwin published the "origin of species", which was the establishment of the initial biological evolution [1]. In 1969, the physicist Prigogine publicly published the theory of dissipative structure [2] for the first time, which is birth of the famous "anti entropy principle": $\mathrm{ds}=\mathrm{dis}+\mathrm{des}<0$, exist in the world of things (including biological and human society) are open System, there is material, information or energy exchange in system and the outside world, when the environmental factor value is greater than the entropy generated in the system, the whole system begins to reduce the entropy, and becomes orderly, regularized. In the 1970s, the birth of synergy theory and catastrophe theory [3] made modern biology, physics, sociology and other fields unified under the command of modern system science. The scientific fusion pattern[4] also made ecology theory successfully transplanted in many disciplines; Therefore, synergetic theory arises. Synergetic theory, which emphasizes mutual promotion and restriction between things, relative to Darwin's biological evolution theory, is more suitable for explaining the evolution of nature systematically after absorbing some principles of self-organization theory of system science. Synergistic ecology incorporates an important influence of the concept

Fund Project: Guangdong Province Graduate Education Innovation Project (Y2150080), Guangdong Provincial Department of Education

Nursery Project( 2012WYM_0013). The Fundamental Research Funds for the Central Universities South China University of Technology (D2156350) of the system in the development process, resulting in an ecosystem (Tansley, 1935; Odum, 1969) [5], system ecology (Odum, 1983) [6] and other works. The concept of ecosystems draws on the principles of system science, combining with previous achievements on ecological evolution, and using the analogical thinking to provide a golden key in the way of opening other areas of research. The emergence of a large number of bionic innovations is the result of a typical ecology transplant of other disciplines, there is an ecological brand system theory with the results of system ecology applied to brand building.

\section{RESEARCH ON ECOLOGICAL BRAND SYSTEM}

\section{A. Research on Ecological Brand in Foreign Countries}

At the end of the 19th century, Alfred Marshall published the "Principles of Economics," which first presented the idea of evolutionary economics [7]; Joseph Schumpeter (Schumpeter) first used system evolution to explain the phenomenon of the economic field, pointing out that entrepreneurs reorganize and use resources, and a new change is the internal driving force of economic activity [8]. In 1982, the American scholar Nelson (R. Nelson) and Winter (S. Winter) of the "evolution of economic evolution theory," put forward the theory of innovation and evolution, argue that the practice, genetic and reproduction, novelty produce variation, search and adaptationideas and so on [9],which explains that the evolution of the enterprise similar to evolutionary principle, that is, variability, inheritance and natural selection of three mechanisms [10]. Upshaw, an American brand expert, thinks the brand is "a complex creature [11] ", Franzen, in his book "science and art of the brand", argues that the brand is a complex, interconnected management decision and consumer response system [12] (Franzenand Moriarty, 2008), which was the first time applying the system approach to look at the brand problem. Brand view system organization, organic development trend is more and more recognized, at the same time, (BLACK, 1977; Mac Cormac, 1985) argues that the metaphor method gradually evolved from the rhetoric method to scientific methodology [13], and further for the ecological brand research provides a scientific tool for the development of the brand of science and technology. In 1998, Ken Baskin published "Corporate 
DNA: Inspiration from Biology", analogy to the phenomenon of nature to explain the same complex ecological brand structure, and analogy to the organization and then describe how to follow the natural to build the organizational structure of the enterprise. Joseph Abe published about business ecosystem, and points out that the enterprise is alive [14], brands have the same life and nature organization. Marketing experts Kotler (Philip Kotler) further describes the concentration of brand meaning: nature, profit and value, the enterprise concept, characteristic and consumers [15]. British scholar John Philip Jones (1999): the product has a life cycle, the product where the brand does not follow the product and caught in this state [16]. Pointed out that the elimination of old brands to create new brands, is not appropriate loss of resources.

\section{B. Domestic research dynamic}

Domestic scholars put forward many of their own views on basis of the theory of a large number of foreign researches.

In 1993, Tang Haibin published "Enterprise Life Theory", from the system point of view, borrowing biology, biological evolution theory, philosophy, economics, management and human physiology and anthropology principles, analyzed company operating mechanism and summarized the nature of the meaning. In 1994, Liu Ji Feng edited the "image of the charm", describes the enterprise and the market is a mutual adaptation, mutual substitution, intricate relationship. On one hand, the market is a kind of non-human will for the transfer of the objective existence, On the other hand, the enterprise is the main body of the economic activity of self-existence and self-evolution in the vagaries of the market environment, it is a living organization, with its own will, desire, motivation and goals, whose survival and development depends on the understanding and adaptation to the environment [17]. In 1996, Wang Zhiping's "theory of enterprise life", elaborated the meaning of corporate life, revealing the structure of the company elements and organizational rules, discusses the brand to enhance the competitiveness of ideas and ways [18]. This discussion is of interest to this study. In 1999, Wang Xingyuan had some relevant definitions in "brand ecosystem" [19], for example, competition and cooperation, structure and organization are discussed. For the first time, ecology ported to the brand field, there is some enlightenment significance, but the scope of discussion has limitations, universal significance is not.

\section{A Review of Research Activities at Home and Abroad}

For a long time, domestic and foreign scholars in the ecological brand system has done a lot of research, after the past, bit by bit together, has gradually moved to a huge academic system, however, opinion is numerous, direction are scattered, and each has great limitationsafter sorting, outlined below:

Many researchers base on their own professional direction and their own knowledge structure to explain the brand evolution mechanism, and put forward their own views and related arguments, even a systematic theoretical framework. But a comprehensive and systematic ecological brand formation mechanism of the study has not yet been found, the brand of ecological theory mining still has room for further expansion. It needs peer to continue efforts.

Brand is the ecological growth, which has been the majority of researchers agree, but how to exchange material, information, and energy with its surroundings, and how to follow the natural ecological revelation, so that the brand healthy growth? What is its source of power mechanism? These are theoretical problems that need to be studied in depth. The current theory of brand construction ideas tend to ignore the ecological, emphasis on the method, and even opportunistic, it often artificially exaggerates some of the influencing factors of the actual brand operation, so that many ethnic brands short-lived, and the results of ignoring the objective law are repeatedly staged.

\section{THE ECOLOGICAL ANALYSIS OF THE BRAND}

This paper will discuss the two aspects: the ecological and growth mechanism of the brand system.

\section{A. An Overview of the Ecological Characteristics of the Brand}

Dialectical materialism tells us that everything has the process of producing, developing, mature, recession, and disappearance. The brand is also a thing that must have the course of production, development, stability, death, which similar to all biological phenomena in nature, and the brand also has its biological-like characteristics [20]. Manfred Brewer argues that the survival of the brand can be divided into six stages: start-up, solid, personality, learning, differences and survival of the fittest stage [21], which demonstrated the brand full stage and its cycle. The growth of the brand is a direct witness to the living body. Any brand is not an overnight thing, are from the weak situation experienced a variety of tempered and grow up, for example, Vanke is under the leadership of the founder of Wang Shi, step by step from a local small business, and then gradually grow into today's industry's leading real estate aircraft carrier. Its brand Vanke has become the hearts of the public's flagship; Famous listed companies TBEA, from Xinjiang Uygur Autonomous Region Changji City Special Transformer Factory, Who can not to think of the past is only a small street factory that only had 50 people, gradually developed into the industry as "China's first transformer" after Wang Jun's careful management; Today, Dongpeng Ceramics, a captain of the ceramic industry, whose predecessor is only a Shiwan Township enterprises Dongping pottery factory in Foshan city. There are too many cases of this regard, and there are many small brands gradually bigger, to grow into well-known brands, all follow the objective law of life growth. These cases illustrate the brand is ecological, which emphasis on growth and development. Therefore, the ecological characteristics of the brand are growth and development.

The following compares the similarity between organism growth and brand growth from the perspective of graph. "Fig. 1" 


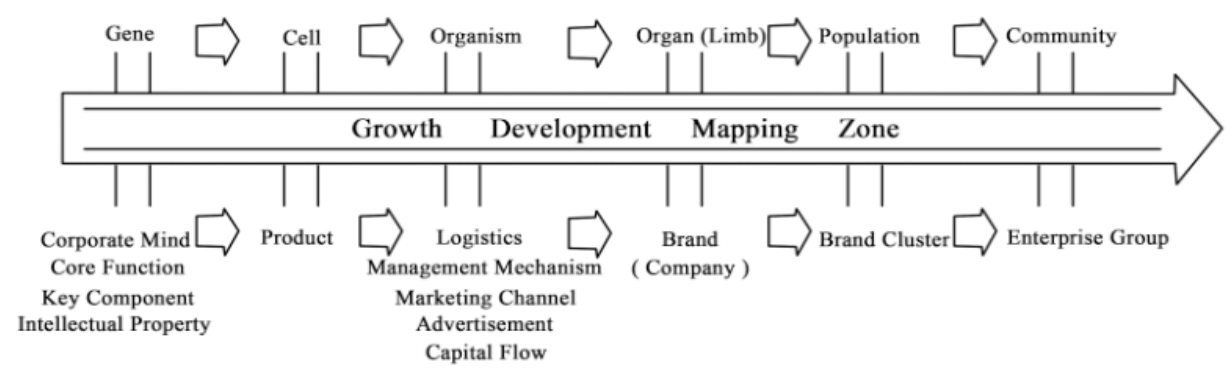

Fig. 1. Brand development process and biological growth process comparison chart [22].

From the above chart, the brand development and biological growth process is similar [23]. The genes of the organisms correspond to the core concepts of the enterprises; The cells of the organisms correspond to the products of the enterprises; The organism of the organism resembles the company's various types of business activities; The organism itself corresponds to the company, and the brand (organization); The biological group corresponds to the brand group; The biological community corresponds to the enterprise group or the industrial cluster. The brand life and the social environment exchange the physical quantity (such as raw materials, logistics, etc.), energy(Such as manufacturing, capital, intellectual property, human resources, etc.) and information(Such as credibility, advertising, influence, market, customer base, etc.), etc, which constitutes a system of interdependence, mutual promotion, co-retreat (circle), and forms the brand organization that has life characteristics, that is, eco-brand ecological and systematic attributes.

\section{B. Several class characteristics of brand organization}

The vitality of the brand must have a good selforganization, self-evolution mechanism, in order to maintain self-renewal, self-repair, adaptation of resources, and to achieve value and have impact resistance, it also needs an adaptive error correction mechanism to maintain their own sustainable survival and growth, and combined with reasonable and orderly management, operational mechanism to thrive. Today many companies do not attach importance to the objective nature of ecological science, blind and too much emphasis on the market manipulation, resulting in a lot of "short-lived brand", such as Qin pool, love and so on. If the subjective will instead of the objective law, out is the only result.

Several features can be summarized from "Fig. 1": (1) Brand organization has an aspect of open side in a particular environment, whose various links exchange with the outside world. The globalization of the economy makes the scope of resource allocation more extensive, so that all aspects of the system are associated with the outside world, which can not exist in isolation, and are likely to be affected by environmental factors and external factors; (2) The market is uncertain, this uncertainty is reflected in uncertainty of the input and output. The uncertainty of new product development and sales affect the uncertainty of brand's development and extinction. That is why people form a diversified theoretical point of view for brand awareness. (3) The ecological brand system has self organization. Under the driving of this characteristic, the ecological brand has the function of adapting to the environment, self evolution and self correcting. This function ensures the growth of the brand.

\section{THE GROWTH MECHANISM AND MOTIVE ForCE OF ECOLOGICAL BRAND}

\section{A. Growth Mechanism and Its Principle}

Brand development relies on the social environment, in which information, material and energy exchange between the brand itself and the environment propels brand growth. Similarly with the exchange between creatures of nature and the external natural environment, the exchange of information, material and energy takes place between brand and socio-economic background, which indicates that the resulting system composed of brand and the external environment that it relies on for survival has the similar signatures with the natural ecosystem. Ecological brand research is actually from two aspects of analysis, that is, the internal system structure and growth mechanism of the study; The study of external growth environment, that is, the study of the relationship between physical quantity(such as raw materials, logistics, etc.), energy(such as manufacturing, capital, intellectual property, human resources, etc.) and information(such as credibility, advertising, influence, market, customer base, etc.) and social environment, and its growth mechanism is similar to the metabolism, that is, continuous innovation.

\section{B. The power source of brand growth mechanism}

The intrinsic dynamics of species evolution in biology is threefold: natural selection, self-organization and random genetic drift. Darwin defines natural selection as "preserving favorable variants, discarding harmful variations"[24]. The theory of biological evolution provides a good reference for brand evolution research. Under the contrast, it can be reasoned that there are three corresponding forces promoting the evolution of the brand: brand self-organization (internal variation, selection), competition between brands (external pressure) and brand opportunities (random factors).

In nature, the basic driving force of biological growth instinct comes from their own DNA information instructions driving the development and expansion of life, then brand's 
basic driving force from where? Trend Expert [US] Daniel Pinker put forward three elements: autonomy, specialization and purpose in his book of "driving force" [25]. We can be understood as a corporate brand in a sense of mission, selfdevelopment in a professional spirit, which is to emphasize the inner side. Enterprises in order to better achieve the value creation and value transfer, will instinctively absorb the stakeholders involved in the system in the way of selfgrowth and mergers, and relating enterprises to establish close ties, etc. This is the enterprise brand ecosystem of instinctive expansion in order to maintain the survival and development of the dominant, which is decided by the brand of DNA survival mission-related information, are endogenous instincts, and can be seen as the basic driving force. In addition, under the industrial structure and other external environmental pressures, enterprises take the initiative to rely on large business, and join in the strength of the system. Such as a large number of auto parts business brands locating in Guangzhou Huadu automobile industry base around attach to Guangzhou Automobile, Dongfeng Nissan and other big brands to survive. At the same time, enterprises and brands face enormous risks and competitive pressures in the era of globalization. Therefore, from the source of the driving force of the brand driving force analysis, it can be divided into two mechanisms: automatic force and his power, which is respectively corresponding to brand selforganization and brand competition theory, as for the genetic drift corresponding to the brand opportunities, because it is based on random elements, which should not be too dependent on, in order to avoid falling into the opportunistic whirlpool.

\section{1) Brand development of the internal driving force}

Internal driving force born in the brand ecosystem, from the brand DNA carried by the corporate culture concept, mission information, entrepreneurial spirit, enterprise-related resources integration capabilities, etc, among them, the entrepreneurial spirit and innovation consciousness is an important promoter. Some studies argues that the brand is the internal elements of the system of mutual cooperation [26]. The generation of self-motivation is related to the entrepreneurial spirit, corporate governance, and the main body of the organization. External dynamic mechanism is related to the competition among brand ecosystems, government industry policy, random factors, technological progress and product input [27].

The automatic force is the force that comes from the inside to promote the advancement of the living body. Internal driving forces is the most basic evolution of nature, which is generally not affected by the outside world. Similarly with the natural life organization, under the influence of the mutual influence and mutual restriction between the components of the brand system, brand system produces internal forces that make the brand grown. Specifically, in the first stage of brand breeds is based on the concept of corporate culture (brand DNA) to formulate the company's brand positioning, the development route, strategy, strategic approach, force direction, object, scope, etc and a series of decision-making. In the function of internal organization system, operating mechanism, etc., the role of mutual support products, services, etc., consciously coordinate each other for moving forward in the direction. Its key depends on the brand gene and the resulting selforganized evolutionary principle. The essence of brand gene is the reaction of the concept of corporate culture and the core values, which provides the basic characteristics of the brand structure and the direction of development; The principle of self-organization determines the establishment of the organizational structure, functional departments, relevant systems and operational mechanisms of the enterprise, and generates the brand's personality characteristics and styles together with the specific environment.

\section{2) The external dynamic mechanism of brand development}

In brand environment, the impact from various influencing factors over brands during the growing process of enterprise brands becomes a driving force which motivates the brand ecology to promote businesses development, this power is called external power. Such as government industry policy, new technology to promote the original industrial upgrading, outside the strong brand invasion, the local similar brand squeeze growth, and the impact of random incident, etc. In the process of brand growth, the increase in entropy generated by itself is a high probability event, which often leads to the reduction or even failure of system efficiency. The external dynamic mechanism often evolved into the conditions of organizational progress. Influence of outside or some form of pressure promote the existing system to improve the utilization of existing resources, to take measures to reduce the phenomenon of entropy increase, to short the cycle of high-tech replacement and compression of industrial transformation time, and to accelerate the growth to consolidate the status of the industry. Many business cases show that the healthy competition between brand ecosystems can accelerate the development of new technologies and objectively promote the upgrading of industries. In addition, the government's industrial policy orientation has an important impact on the growth of brand ecosystems. Some industries can be driven by policy, such as new energy, coping with the aging health care industry, etc.

A typical source of external power is the competition between brands. Competition is both stress and power. The key is to turn pressure into the power of the ability. Some foreign scholars believe that as long as the existence of business, competition will be a driving force [28]. Others, such as the author of "the Blue Ocean Strategy", Money and Kim and Renee and Mobonie, even believe that companies should simply avoid creating competition by creating new markets. This view is biased, creating a new market should be the result of positive innovation, and the majority of business innovation comes from the needs of competition. In other word, with the fierce competition in the same market, the enterprises can survive and develop through innovation, which is a kind of obvious mechanism that external power drives the innovation and change of internal enterprise. It also shows that in most cases, the external dynamic 
mechanism and the internal dynamic mechanism are organically combined, and the external motive force can be transformed into internal power under certain conditions.

\section{CONCLUSION}

Through the preliminary analysis of the brand system ecology, self-organization, system coordination, openness, uncertainty, we can get a revelation: The brand system is a complex system with life, which has the similar biological growth mechanism and its driving force principle. In the process of building a national brand in the brand ecosystem must follow the objective and systematic rules, to understand the formation mechanism and principle, to develop scientific and rational brand planning, to build a strong brand vitality of the Chinese nation. Through these to help the majority of brand operations and managers.

\section{REFERENCES}

[1] Ma Jianhua, Guan Hua. System science and its application in geographical science [M]. Beijing: Science Press, 2003.3:100-111.

[2] ShenXiaofeng, Hu Gang, Jiang Lu. Establishment of the theory of dissipative structure [J]. natural dialectics research, 1986 (06):45-49.

[3] Chen Kuining. "The revelation of new three" -- on the dissipative structure theory, coordination theory and catastrophe theory [J]. Science \& technology, 1987 (01):40-42

[4] Yin Hongchun, study on complex adaptability and co evolution of eco brand system [D]. Tianjin: Tianjin University, 2005:10-20.

[5] Wang Xianpu, the concept of ecological system and its research direction [J]. environmental protection.1978 (06): 5-8.

[6] Zhang Xiaoai, Deng Heli. The organization theory of the ecosystem: the dynamic theory of food chain and mutualism symbiosis. Cybernetics [J]. zoological research, 1996 (04): 429-430.

[7] Shaw, AI Jiao. Evolutionary Economics: origin and development [J]. Foreign Social Sciences, 2001 (04): 17-20.

[8] Yan Liang Gong. Annual bear Pete growth theory: a literature review [J]. Economics (quarterly), 2009 (03): 1163

[9] (US) Richard.R. Nelson. Evolutionary theory of economic change [M]. translated by $\mathrm{Hu}$ Shikai. Beijing: the Commercial Press, December 1997: 3-11.

[10] Hu Daiguang, Wu Yifeng, Ding Bing. New trends of foreign economics and the development of China's economics [M]. Beijing: Economic Science Press, first edition, December 1998: 299

[11] Lynn b. Upshaw. Brand characteristics, market competition strategy to success [M]. Beijing: tsinghua university press, 2001:11.

[12] GiepFranzen, Sandra E. Moriarty. The Science and Art of Branding[M]. M.E. Sharpe 2008:10.

[13] Quan-guozhu. Black metaphor examples analysis [J]. Journal of jiangxi social science. 2011 (8) : 213-217.

[14] Joseph Abe, KandiahGajen.The New Business Ecosystem[J]. Strategy \&Leadership, 1998,25 (5) : 28〜 33 .

[15] (US) Kotler (PhilipKotler). Marketing management (Ninth Edition) [M]. Mei Ruhe et al. Shanghai: Shanghai people's publishing house, 1999:10.

[16] Chen Fang. Brand [M]. Beijing: Current Affairs Press, 2002.1.

[17] Liu Jifeng and. The charm of image CIS theory and method [M]. Beijing: China Economic Press, first edition, December 1994: (in Chinese), 11

[18] Wang Ziping. Trek set - Prince Ping on teaching and academic [M]. Beijing: China land press, 2008.7:89-90.

[19] Wang Xingyuan. Characteristics and balance of interests of famous brand ecosystem $[\mathrm{J}]$. business research, $2000(10): 8 \sim 10$
[20] (United States) Kotler, Armstrong. Introduction to Marketing [M]. Yu Lijun translation, Beijing: Huaxia Publishing House, 2000.9: 212 214.

[21] Manfred Brunn, Professor of European Studies at the European Institute of Economics, presents six different stages of the brand, which are different from the brand stage delineated by most economists and marketing experts, especially in the stage of personality and learning, for the brand's understanding of a unique view - the author note.

[22] Reference Yin Hongchun on the development of ecological map ideas. - the author note

[23] Gerard Prendergast, Pierre Berthon, Insights from Ecology : An EcotonePerspective of Marketing[J]. European Management Journal, 2000, 18(2) : 223 232

[24] [English]. Darwin on the origin of species [M]. Beijing: the commercial press, 1997:95.

[25] [US] Daniel pink. Driving force.Drive: The Surprising Truth about What Motivates Us[M]. Gong Yi translation. Beijing: Renmin University of China Press, 2012-2.

[26] Wang Xingyuan. Development trend of brand ecology and its application [J] .Enterprise Economy, 2014 (07): 5-8.

[27] WANG Xing-yuan, YU Wei, ZHANG Peng.Studies on the characteristics, growth mechanism and formation pattern of high-tech brand ecosystem [J]. Science and Technology Progress and Countermeasures, 2009 (1): 87-90.

[28] Orsato (Italy), Li Yue, translation, sustainable development strategy: "turning green" when the enterprise returns [M]. Beijing: China Machine Press. 